\title{
USE OF ACTIVATED CARBON FROM SAPINDUS FOR THE ADSORPTION OF METHYLENE BLUE
}

\author{
Taous Hamad ${ }^{1}$, Zoubir Benmaamar ${ }^{2}$, Mohamad Nedjioui ${ }^{1}$ and Ahmed Boucherit ${ }^{3}$ \\ ${ }^{1}$ Département de génie des procédés, faculté des sciences de l'ingénieur, université de Médéa, Algeria. \\ ${ }^{2}$ Laboratoire d'Application Energétique de l'Hydrogène, University of Blida 1, Algeria. \\ ${ }^{3}$ Laboratory of Chemical Engineering, University Saad Dahlab of Blida 1, P.O. Box 270, Blida, Algeria. \\ benmaamarzoubir@yahoo.fr
}

(Received 3 April 2017 - Accepted 18 January 2018)

\begin{abstract}
Hamad, Taous, Zoubir Benmaamar, Mohamad Nedjioui and Ahmed Boucherit. 2018. Use of activated carbon from sapindus for the adsorption of methylene blue. Lebanese Science Journal, 19(1): 112-122.

Activated carbon was produced from Sapindus fruit residue and was used for the adsorption of methylene blue dye from simulated aqueous solution. Adsorption kinetics of methylene blue onto actived carbon were studied in a batch system. The effects of $p H$ and contact time were examined. The goal of the present study was the determination of the optimal experimental conditions. The maximum adsorption of methylene blue occurred at pH 6.0 $(4.83 \mathrm{mg} / \mathrm{g})$ and the lowest adsorption occurred at $\mathrm{pH} 2.0(4.35 \mathrm{mg} / \mathrm{g}) .120 \mathrm{~min}$ was the time needed for apparent equilibrium. Adsorption modelling was determined by using the Freundlich and Langmuir isotherms. Data were interpreted based on $R^{2}$ and various error distribution functions. Adsorption isotherm was best described by non linear Freundlich isotherm model. In order to determine the best-fit-adsorption kinetics, the experimental data were analyzed using pseudo-first-order, pseudo-second-order, pseudo-third-order, Esquivel, and Elovich models. The needed relative parameters were determined by linear and non-linear regressive methods. The statistical functions were estimated to find the suitable method which fit the experimental data. Both methods were suitable to obtain the required parameters. The model that best fit the present equilibrium data was the linear Elovich model (type 1 and 2). The present work showed that activated carbon can be used as a low cost adsorbent for the methylene blue removal from aqueous solutions.
\end{abstract}

Keywords: Activated carbon (AC), methylene blue (MB), modelling, linear regression, non-linear regression.

\section{INTRODUCTION}

In coloring paper, dyeing cottons, wools, silk, leather and coating for paper stock, methylene blue (MB) is used. The treatment of effluents containing such dyes is of great interest due to its harmful impacts on receiving water (Kushwaha et al., 2014). The best efficient method used for the quick removal of dyes from aqueous solutions was physical adsorption (Allen et al., 2005). A slightly better adsorption was shown by aromatic solutes compared to aliphatic solutes, due to the potential to form $\pi-\pi$ bonds with the basal planes of activated carbon. No significant influence of solute charge or size was observed (De Ridder, 2012).

Adsorption process was used for the elimination of pollutant from simulated aqueous solution and is extremely influenced by the medium of the solution, which affects the adsorption rate, the nature of the adsorbent surface charge, the aqueous adsorbate species speciation and the ionization extent. Functional dissociation groups on the adsorbate and adsorbent were affected by a pH change during the adsorptive process (Khattria et al. 2009).

In this study, the potential of activated carbon (AC) was evaluated to remove MB dye from simulated aqueous solutions in batch mode.

http://dx.doi.org/10.22453/LSJ-019.1.112-122 National Council for Scientific Research - Lebanon 2018@ 1sj.cnrs.edu.lb/vol-19-no-1-2018/ 


\section{MATERIALS AND METHODS}

MB (3, 7-bis (Dimethylamino)-phenazathionium chloride tetramethylthionine chloride, $\mathrm{C}_{16} \mathrm{H}_{18} \mathrm{~N}_{3} \mathrm{SCl} \cdot 3 \mathrm{H}_{2} \mathrm{O}$, $\mathrm{Mw}=373.9 \mathrm{~g} / \mathrm{mol}$, Figure 1) used in the present study was purchased from Merck (Germany), being selected from the list of dyes normally used in Algeria.<smiles></smiles>

Figure 1. Structure of methylene blue (Al-Degs et al. 2012).

The activated carbon was prepared as reported earlier (Lam 2008). The fruit of Sapindus fruit was collected from Bousmail (Algeria). The fruit of Sapindus was sieved in order to obtain a desirable size fraction $(0.5$ and $1 \mathrm{~mm})$. The sieved residue of Sapindus fruit was then washed with distilled water to remove any residues or impurities. Subsequently, it was dried in an oven for 12 hours at $80^{\circ} \mathrm{C}$. After drying, the material was pyrolysized in a fluidized bed furnace at 300,400 and $500{ }^{\circ} \mathrm{C}$ for half an hour. The char produced was then discharged from the first cyclone of the fluidized bed furnace. This fast pyrolysis method produced a variety of char at different temperatures.

Activation of the char was done by using a steam average flowrate of $300 \mathrm{ml} / \mathrm{min}$ at temperature of $800^{\circ} \mathrm{C}$ in a muffle furnace for 1 and 2 hours. The activated carbon was then ground and dried overnight in an oven at $100{ }^{\circ} \mathrm{C}$.

The adsorption parameters were optimized. In each experiment pre-weighed amount of adsorbent (50 $\mathrm{mg}$ ) was added to $50 \mathrm{~mL}$ of dye solution $(5 \mathrm{mg} / \mathrm{L})$ taken in a conical flask of $250 \mathrm{~mL}$ and $0.1 \mathrm{M} \mathrm{NaOH}$ or $0.1 \mathrm{M} \mathrm{HCl}$ were added to adjust the $\mathrm{pH}$ value. This solution was agitated at $300 \mathrm{rpm}$ and centrifuged. A spectrophotometer UV-1700 PHARMA SPEC SHIMADZU was used for determining the MB concentration in aqueous solution at $\lambda_{\max }=665 \mathrm{~nm}$. The adsorbed amount of MB per mass unit of adsorbent at time t, q (mg/g), (Equation 1) and the dye removal efficiency (R \%) (Equation 2) were calculated as follows:

$$
\begin{aligned}
& q=\left(C_{0}-C\right) \frac{V}{M} \\
& R=\frac{\left(C_{0}-C\right)}{C_{0}} \times 100
\end{aligned}
$$

Where $\mathrm{C}_{0}$ is the initial concentration of $\mathrm{MB}(\mathrm{mg} / \mathrm{L}), \mathrm{C}$ is the $\mathrm{MB}$ concentration at time $\mathrm{t}, \mathrm{V}$ is the volume of solution (L) and $\mathrm{M}$ is the adsorbent mass (g) (Santhi et al., 2009).

By mixing $1 \mathrm{~g}$ of the adsorbent with $1 \mathrm{~L}$ of the $\mathrm{MB}$ simulated aqueous solution of $5 \mathrm{mg} / \mathrm{L}$, the effect of $\mathrm{pH}$ was evaluated. The $\mathrm{pH}$ value varied from 2 to 12 , by adding $0.1 \mathrm{M} \mathrm{NaOH}$ or $0.1 \mathrm{M} \mathrm{HCl}$ solutions. The suspension was shaken for $24 \mathrm{~h}$ at $25^{\circ} \mathrm{C}$. Kinetic experiments were performed by mixing $50 \mathrm{~mL}$ of dye solution $(5 \mathrm{mg} / \mathrm{L})$ with $50 \mathrm{mg}$ $(0.05 \mathrm{~g})$ of adsorbent for different periods $(5,10,15,20,25,30,40,50,60,90,120,180,240$ and $300 \mathrm{~min})$. The initial $\mathrm{pH}$ for each dye solution was set at $6 . \mathrm{MB}$ concentration in the supernatants was determined and the adsorbed amount of MB was calculated by equation 1 .

\section{RESULTS AND DISCUSSION}

Adsorption isotherms are important for the description of how adsorbates will interact with an adsorbent. Thus, the correlation of equilibrium data using either a theoretical or empirical equation is essential for the adsorption data and prediction, as well. For further interpretation of the obtained adsorption data the two famous isotherm equations, the Langmuir and Freundlich isotherm equations, were employed.

The adsorption of $\mathrm{MB}$ increased with increasing the $\mathrm{pH}$ of the solution. The best value of adsorption 
capacity, qe $=4.83 \mathrm{mg} / \mathrm{g}$, was recorded at pH 6 (Fig. 2).

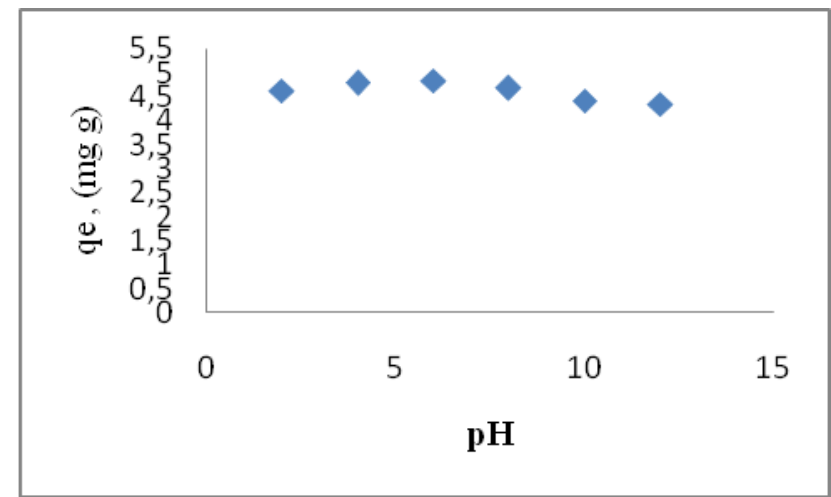

Figure 2. Effect of the initial $\mathrm{pH}$ on the AC equilibrium adsorption capacity.

In the basic medium, the negatively charged species of the adsorbent tended to dominate leading to a more negatively charged surface. In this case, the adsorbent surface was negatively charged. The MB adsorption increased due to the enhancement of electrostatic attractions between the negative charge of AC particles and the positive charge of MB species.

In order to determine the best-fit-adsorption isotherms, the experimental data were analyzed using Freundlich and Langmuir equations. Equations of these models (Fadi Al Mardini et al., 2009) are presented in Table 1, where $\mathrm{q}$ is the equilibrium dye concentration on adsorbent $(\mathrm{mg} / \mathrm{g}), \mathrm{q}_{\mathrm{m}}$ is the monolayer capacity of the adsorbent $(\mathrm{mg} / \mathrm{g}), \mathrm{C}$ is the equilibrium dye concentration in solution $(\mathrm{mg} / \mathrm{L}), \mathrm{K}_{\mathrm{L}}$ is the Langmuir adsorption constant representing the energy constant related to the heat of adsorption, $\mathrm{n}$ and $\mathrm{K}_{\mathrm{F}}$ are Fruendlich constants related to adsorption intensity of the adsorbent and adsorption.

Table 1. Adsorption isotherms models and their linear and non linear forms (Fadi Al Mardini et al. 2009)

\begin{tabular}{|c|c|c|}
\hline Applied model & Linear form & Non Linear form \\
\hline \multirow[t]{2}{*}{ Langmuir 1} & $C \quad C, 1$ & $q \quad K_{L} C$ \\
\hline & $\bar{q}=\overline{q_{m}}+\overline{k_{L} q_{m}}$ & $\overline{q_{m}}=\overline{1+K_{L} C}$ \\
\hline Langmuir 2 & $\frac{1}{-}=\frac{1}{C} \frac{1}{X}+\frac{1}{-}$ & \\
\hline & $\begin{array}{llll}q & C & q_{m} K_{L} & q_{m} \\
\end{array}$ & \\
\hline Langmuir 3 & $q=\frac{1}{K_{L}} \frac{q}{C}+q_{m}$ & \\
\hline Langmuir 4 & $q=-\frac{1}{K_{L}} \frac{q}{C}+q_{m}$ & \\
\hline Langmuir 5 & $\frac{q}{C}=-K_{L} q+K_{L} q_{m}$ & \\
\hline Langmuir 6 & $\frac{1}{C}=K_{L} q_{m} \frac{1}{q}-K_{L}$ & \\
\hline Freundlich & $\ln (q)=\ln \left(k_{F}\right)+n \ln (C)$ & $q=K_{F} C^{1 / n}$ \\
\hline
\end{tabular}

Excel and Origin software were used respectively for the non-linear and linear fitting procedure. The constants of all models are given in Table 2. 
TABLE 2. Constants for linear and non-linear Langmuir and Freundlich isotherms related to the adsorption of MB onto AC.

\begin{tabular}{|c|c|c|}
\hline Model & Linear method & Non-linear method \\
\hline $\begin{array}{l}\text { Langmuir 1 } \\
\mathrm{q}_{\mathrm{m}} \\
\mathrm{K}_{\mathrm{L}} \\
\mathrm{R}^{2}\end{array}$ & $\begin{array}{l}-76.923 \\
-1.625 \\
0.643\end{array}$ & \multirow[t]{6}{*}{$\begin{array}{l}161468.291 \\
1.370 * 10^{-3} \\
0.983\end{array}$} \\
\hline $\begin{array}{l}\text { Langmuir } 2 \\
\mathrm{q}_{\mathrm{m}} \\
\mathrm{K}_{\mathrm{L}} \\
\mathrm{R}^{2}\end{array}$ & $\begin{array}{l}-66.667 \\
-1.875 \\
0.869\end{array}$ & \\
\hline $\begin{array}{l}\text { Langmuir } 3 \\
\mathrm{q}_{\mathrm{m}} \\
\mathrm{K}_{\mathrm{L}} \\
\mathrm{R}^{2}\end{array}$ & $\begin{array}{l}-58.740 \\
1.949 \\
0.363\end{array}$ & \\
\hline $\begin{array}{l}\text { Langmuir } 4 \\
\mathrm{q}_{\mathrm{m}} \\
\mathrm{K}_{\mathrm{L}} \\
\mathrm{R}^{2}\end{array}$ & $\begin{array}{l}-58.740 \\
-1.949 \\
0.363\end{array}$ & \\
\hline $\begin{array}{l}\text { Langmuir } 5 \\
\mathrm{q}_{\mathrm{m}} \\
\mathrm{K}_{\mathrm{L}} \\
\mathrm{R}^{2}\end{array}$ & $\begin{array}{l}-0.008 \\
-0.708 \\
0.363\end{array}$ & \\
\hline $\begin{array}{l}\text { Langmuir } 6 \\
\mathrm{q}_{\mathrm{m}} \\
\mathrm{K}_{\mathrm{L}} \\
\mathrm{R}^{2}\end{array}$ & $\begin{array}{l}-0.003 \\
-2.733 \\
0.869\end{array}$ & \\
\hline $\begin{array}{l}\text { Freundlich } \\
\mathrm{n} \\
\mathrm{K}_{\mathrm{F}} \\
\mathrm{R}^{2}\end{array}$ & $\begin{array}{l}1.251 \\
301.569 \\
0.949\end{array}$ & $\begin{array}{l}0.911 \\
243.527 \\
0.989\end{array}$ \\
\hline
\end{tabular}

The coefficient of correlation indicated that Freundlich isotherm fitted the experimental data better than Langmuir isotherm. Good agreement between the experimental isotherms and the Freundlich model was found in the case of systems: Methylene Blue/Cactus (Sakr et al. 2015), pentachlorophenol/(M)Al-MCM-41 (Marouf-Khelifa et al. 2004), and toluene/actived Carbon (Benkhedda et al. 2000).

The optimization procedure has required a defined error function in order to evaluate the fit of equation to the experimental data. The best-fitting equation is determined using the well-known special functions to calculate the deviation error between experimental and predicted data. The mathematical equations of these error functions are illustrated in Table 4. 
Table 3. Mathematical equations of error functions.

\begin{tabular}{|c|c|c|}
\hline Error functions & Equations & Reference \\
\hline MPSED & $M P S E D=\sqrt{\frac{\sum\left[\left(q_{\mathrm{exp}}-q_{\text {calc }}\right) / q_{\mathrm{exp}}\right]^{2}}{(n-p)}}$ & (Ncibi 2008) \\
\hline ARE & $A R E=\frac{\sum\left|\left(q_{c a l c}-q_{\mathrm{exp}}\right) / q_{\mathrm{exp}}\right|}{n}$ & (Han et al. 2009) \\
\hline ARS & $A R S=\sqrt{\frac{\sum\left[\left(q_{\exp }-q_{c a l c}\right) / q_{\exp }\right]^{2}}{(n-1)}}$ & (Han et al. 2009) \\
\hline HYBRID & HYBRID $=\frac{1}{(n-P)} \sum_{i=1}^{n}\left|\frac{q_{\exp }-q_{\text {calc }}}{q_{\exp }}\right|_{i}$ & (Gulipall et al. 2011) \\
\hline
\end{tabular}

Where $n$ is the number of experimental data points, $q_{\text {calc }}$ is the predicted (calculated) quantity of MB adsorbed onto AC, $\mathrm{q}_{\mathrm{exp}}$ is the experimental data, $\mathrm{p}$ is the number of parameters in each kinetic model, ARE is the average relative error (dimensionless parameter), ARS is the average relative standard error (dimensionless parameter), HYBRID is the hybrid fractional error function (dimensionless parameter) and MPSED Marquardt's is the percent standard deviation (dimensionless parameter). The constants of all error analysis are presented in Table 4.

Table 4. Error deviation data related to the adsorption of MB onto AC employing the most commonly used functions.

\begin{tabular}{|c|l|l|}
\hline Error functions & Linear Freundlich model & Non linear Freundlich model \\
\hline MPSED & 2.066 & 0.316 \\
\hline HYBRID & 2.095 & 0.255 \\
\hline ARE & 1.496 & 0.182 \\
\hline ARS & 1.886 & 0.288 \\
\hline
\end{tabular}

The isotherm adsorption data are essentially required for designing the adsorption systems. In order to optimize the design of a specific sorbate/sorbent system for the removal of MB from aqueous solution, it was important to establish the most appropriate correlation for the experimental kinetic data.

Applicability of some statistical tools to predict the optimum adsorption isotherms of MB onto AC after linear regression analysis showed that the highest $\mathrm{R}^{2}$ value and the lowest ARE, ARS, MSPED, and HYBRID values can be suitable and meaningful tools to predict the best-fitting equation models.

The best fitting was determined based on the use of these functions for the calculation of the deviation error between experimental and predicted equilibrium adsorption isotherm data, after linear analysis. Consequently, from Table 3, it seems that the most suitable model for the study of adsorption phenomenon is the non linear Freundlich model. Therefore, based on the mentioned results, the best useful estimation error of the statistical tools pointed out to the non linear Freundlich model, followed by linear Freundlich model, as the best-fitting models.

Figure 3 illustrates the effect of contact time on decolorization (dye adsorption) with AC. The plot (simulated aqueous solution) can be divided in three zones: (i) 0-30 min, which indicated the fast adsorption of MB, suggesting rapid external diffusion and surface adsorption; (ii) 30-60 $\mathrm{min}$, shows a gradual equilibrium, and (iii) 60-300 min, indicates the plateau of the equilibrium state. At the initial stage of the contact the adsorption was rapid, but it gradually slowed down until the equilibrium. At the initial stage the fast adsorption can be attributed to the fact that a large number of surface sites are available for adsorption. 
The remaining surface sites are difficult to be occupied after a lapse of time. Adsorption is a complex process which is influenced by several parameters related to adsorbent and to the physicochemical conditions, under which the process is carried out (Dahri et al. 2014).

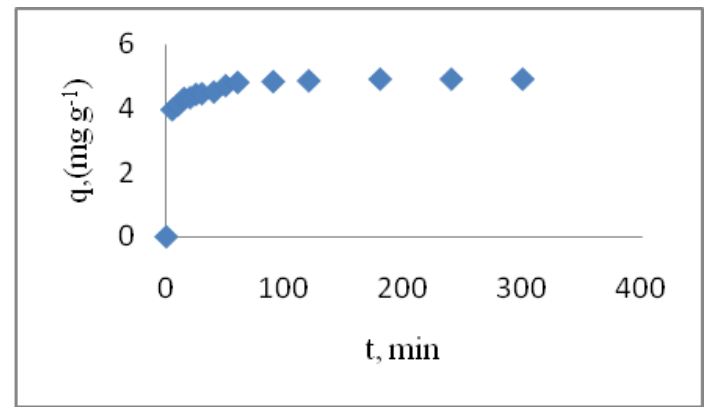

Figure 3. MB adsorption kinetic on AC.

The following equations: Pseudo-first order, Pseudo-second order, Esquivel, Pseudo-third order and Elovich were used for understanding the mechanism of the adsorption process study and were selected to fit the experimental kinetic data. Equations and the constants of these models are presented in Table 6.

Table 5. A linear and non-linear Pseudo-first order, Pseudo-second order, Esquivel, Pseudo-third order and Elovich kinetics isotherms constants related to the adsorption of $\mathrm{MB}$ onto $\mathrm{AC}$.

\begin{tabular}{|c|c|c|c|}
\hline Linear Method & Reference & Non-linear Method & Reference \\
\hline $\begin{array}{l}\text { Pseudo-first order (type 1) } \\
\log \left(q_{e}-q\right)-\log \left(q_{e}\right)=-\frac{k_{1} t}{2.303} \\
\mathrm{q}_{\mathrm{e}}=4.901 \\
\mathrm{~K}_{1}=0.037 \\
\mathrm{R}^{2}=0.727\end{array}$ & (Kumar 2006) & $\begin{array}{l}\text { Non-linear Pseudo- } \\
\text { first order (type 1) } \\
q=q_{e}\left(1-e^{-k_{1}}\right) \\
\mathrm{q}_{\mathrm{e}}=4.642 \\
\mathrm{~K}_{1}=0.333 \\
\mathrm{R}^{2}=0.962\end{array}$ & $\begin{array}{l}\text { (Kumar } \\
\text { 2006) }\end{array}$ \\
\hline $\begin{array}{l}\text { Pseudo-first order (type 2) } \\
\ln \left(q_{e}-q\right)-\ln \left(q_{e}\right)=-k_{1} t \\
\mathrm{q}_{\mathrm{e}}=4.901 \\
\mathrm{~K}_{1}=0.036 \\
\mathrm{R}^{2}=0.727\end{array}$ & (Tavlieva et al. 2013) & & \\
\hline $\begin{array}{l}\text { Pseudo-first order (type 3) } \\
\ln \left(\frac{C}{C_{0}}\right)=k_{1} t \\
\mathrm{C}_{0}=5.000 \\
\mathrm{~K}_{1}=0.019 \\
\mathrm{R}^{2}=-1.000\end{array}$ & (Rao et al. 2011) & \multirow[t]{2}{*}{$\begin{array}{l}\text { Non-linear Pseudo- } \\
\text { first order (type 2) } \\
C=C_{0} e^{-k_{1} t} \\
\mathrm{C}_{\mathrm{o}}=5.000 \\
\mathrm{~K}_{1}=0.230 \\
\mathrm{R}^{2}=0.894\end{array}$} & \multirow[t]{2}{*}{$\begin{array}{l}\text { (Pereira et } \\
\text { al. 2012) }\end{array}$} \\
\hline $\begin{array}{l}\text { Pseudo-first order (type 4) } \\
\ln \left[1-\frac{C_{0}-C}{C_{0}-C_{e}}\right]=k_{1} t \\
\mathrm{C}_{0}=5.000 \\
\mathrm{~K}_{1}=0.005 \\
\mathrm{R}^{2}=-0.690\end{array}$ & (Rao et al. 2011) & & \\
\hline $\begin{array}{l}\text { Pseudo-second order (type } \\
\text { 1) } \\
\frac{t}{q}=\frac{1}{k_{2} q_{e}^{2}}+\frac{t}{q_{e}} \\
\mathrm{q}_{\mathrm{e}}=4.950 \\
\mathrm{~K}_{2}=0.080 \\
\mathrm{R}^{2}=0.999\end{array}$ & (Ho 2006) & $\begin{array}{l}\text { Non-linear Pseudo- } \\
\text { second order } \\
q=\left[\frac{q_{e}^{2} k_{2} t}{1+k_{2} q_{e} t}\right] \\
\mathrm{q}_{\mathrm{e}}=4.829 \\
\mathrm{~K}_{2}=0.666\end{array}$ & $\begin{array}{l}\text { (Kumar } \\
2006) \\
\text { (Kumar } \\
2006)\end{array}$ \\
\hline
\end{tabular}




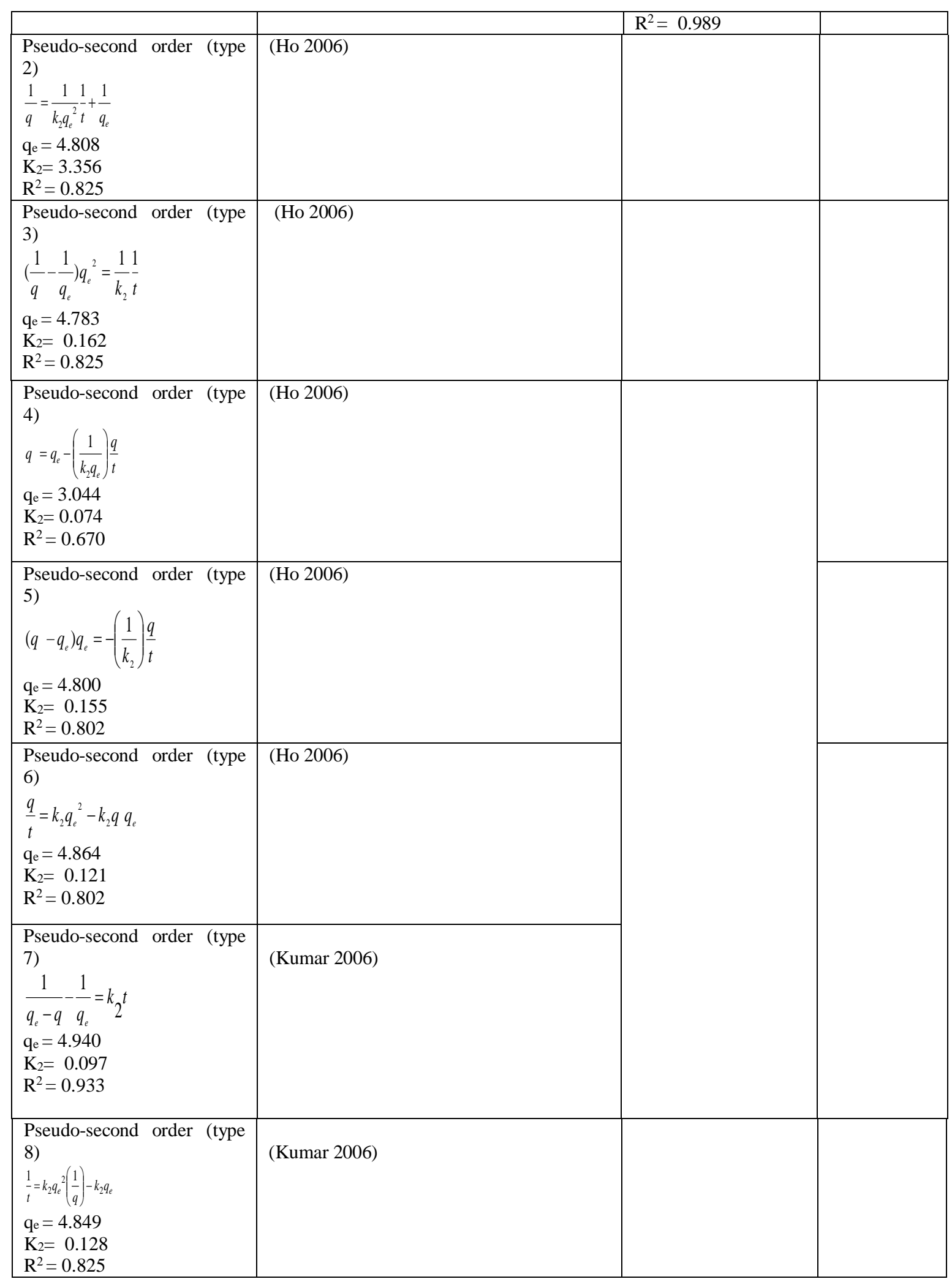




\begin{tabular}{|c|c|c|c|}
\hline $\begin{array}{l}\text { Pseudo-second order (type } \\
\text { 9) } \\
\frac{q_{e}}{q_{e}-q}-1=k_{2} t \\
\mathrm{q}_{\mathrm{e}}=4.940 \\
\mathrm{~K}_{2}=0.483 \\
\mathrm{R}^{2}=0.933\end{array}$ & (Ho 2006) & & \\
\hline $\begin{array}{l}\text { Pseudo-second order (type } \\
10 \text { ) } \\
\frac{\theta}{1-\theta}=k_{2} t \\
\mathrm{q}_{\mathrm{e}}=4.940 \\
\mathrm{~K}_{2}=0.483 \\
\mathrm{R}^{2}=0.933\end{array}$ & (Ho 2006) & & \\
\hline $\begin{array}{l}\text { Pseudo-second order (type } \\
\text { 11) } \\
C-\frac{1}{C_{0}}=k_{2} t \\
\mathrm{C}_{0}=5.000 \\
\mathrm{~K}_{2}=-7 * 10^{-3} \\
\mathrm{R}^{2}=-0.200\end{array}$ & (Pereira et al. 2012) & & \\
\hline $\begin{array}{l}\text { Pseudo-second order (type } \\
\text { 12) } \\
\frac{1}{C}-\frac{1}{C_{0}}=k_{2} t \\
\mathrm{C}_{0}=5.000 \\
\mathrm{~K}_{2}=0.042 \\
\mathrm{R}^{2}=0.855\end{array}$ & (Ho 2000) & & \\
\hline $\begin{array}{l}\text { Pseudo-second order (type } \\
\text { 13) } \\
\frac{1}{C_{0}-C}=k_{2} t+b \\
\mathrm{C}_{0}=5.000 \\
\mathrm{~K}_{2}=0.000 \\
\mathrm{R}^{2}=0.539\end{array}$ & (Blanachard et al. 1984) & & \\
\hline $\begin{array}{l}\text { Esquivel Model (type 1) } \\
\frac{1}{q}=\left(\frac{K_{E}}{q_{e}}\right) \frac{1}{t}+\frac{1}{q_{e}} \\
\mathrm{q}_{\mathrm{e}}=4.807 \\
\mathrm{~K}_{\mathrm{E}}=1.308 \\
\mathrm{R}^{2}=0.825\end{array}$ & (Shilpi et al. 2013) & \multirow[t]{2}{*}{$\begin{array}{l}\text { Non-linear Esquivel } \\
\text { Model } \\
q=q_{e}\left(\frac{t}{t+K_{E}}\right) \\
\mathrm{q}_{\mathrm{e}}=4.829 \\
\mathrm{~K}_{\mathrm{E}}=1.502 \\
\mathrm{R}^{2}=0.989\end{array}$} & \multirow[t]{2}{*}{$\begin{array}{l}\text { (Shilpi et al. } \\
2013)\end{array}$} \\
\hline $\begin{array}{l}\text { Esquivel Model (type 2) } \\
\left(\frac{1}{q}-\frac{1}{q_{e}}\right) q_{e}=K_{E} \frac{1}{t} \\
\mathrm{q}_{\mathrm{e}}=4.783 \\
\mathrm{~K}_{\mathrm{E}}=1.285 \\
\mathrm{R}^{2}=0.825\end{array}$ & (Shilpi et al. 2013) & & \\
\hline
\end{tabular}




\begin{tabular}{|l|l|l|l|}
\hline Pseudo-third order & (Ho et al. 2000) & & \\
$\frac{1}{q^{2}}=\frac{1}{q_{e}^{2}}+k_{3} t$ & & & \\
$\mathrm{q}_{\mathrm{e}}=4.344$ & & & \\
$\mathrm{~K}_{3}=-6^{*} 10^{-5}$ & & \\
$\mathrm{R}^{2}=0.519$ & ( Ho et al. 2002) & & \\
\hline Elovich (type1) & & \\
$q=k_{5} \ln \left(k_{5} k_{4}\right)+k_{5} \ln (t)$ & & \\
$\mathrm{K}_{4}=6350477$ & & \\
$\mathrm{~K}_{5}=0.252$ & & \\
$\mathrm{R}^{2}=0.932$ & (Tavlieva et al. 2013) & & \\
\hline Elovich (type 2$)$ & & \\
$q=\left(1 / k_{5}\right) \ln \left(k_{5} k_{4}\right)+\left(1 / k_{5}\right) \ln (t)$ & $\mathrm{K}_{4}=$ & & \\
403281 & & \\
$\mathrm{~K}_{5}=3.968$ & & \\
$\mathrm{R}^{2}=0.932$ & & \\
\hline
\end{tabular}

where $\mathrm{k}_{1}$ is Pseudo-first order rate constant $\left(\mathrm{min}^{-1}\right), \mathrm{k}_{2}$ is Pseudo-second order rate constant $(\mathrm{g} /(\mathrm{mg} \min ))$, $\mathrm{k}_{3}$ is Pseudo-third order rate constant $\left(\mathrm{g}^{2} /\left(\mathrm{mg}^{2} \mathrm{~min}\right)\right), \mathrm{K}_{\mathrm{E}}$ is Esquivel rate constant $(\mathrm{min}), \mathrm{k}_{4}$ is Elovich rate constant $(\mathrm{mg} /(\mathrm{g}$ $\min )$ ), $\mathrm{k}_{5}$ is extent of surface coverage and activation energy of the process $(\mathrm{g} / \mathrm{mg}), \mathrm{k}_{6}$ extent of surface coverage and activation energy of the process $(\mathrm{g} / \mathrm{mg})$, $\mathrm{k}_{7}$ Elovich rate constant $(\mathrm{mg} /(\mathrm{g} \min ))$, $\mathrm{q}_{\mathrm{e}}$ is amount of adsorption at equilibrium $(\mathrm{mg} / \mathrm{g})$, and $\theta$ dimensionless parameter $\left(=\mathrm{q} / \mathrm{q}_{\mathrm{e}}\right)$.

The constants of all error analysis are represented in Table 6.

Table 6. Error deviation data related to the MB adsorption onto AC employing most commonly used functions.

\begin{tabular}{|l|l|l|l|l|l|}
\hline \multicolumn{1}{|c|}{ Error functions } & $\begin{array}{c}\text { Linear Elovich } \\
\text { model (type 1 } \\
\text { and 2) }\end{array}$ & $\begin{array}{c}\text { Linear pseudo } \\
\text { second order } \\
\text { type 9 and 10) }\end{array}$ & $\begin{array}{c}\text { Non-linear } \\
\text { esquivel } \\
\text { model }\end{array}$ & $\begin{array}{c}\text { Non-linear } \\
\text { pseudo } \\
\text { second order }\end{array}$ & $\begin{array}{c}\text { Linear esquivel } \\
\text { model (type 2) }\end{array}$ \\
\hline MPSED & 0.018 & 0.040 & 0.031 & 0.031 & 0.047 \\
\hline HYBRID & 0.016 & 0.025 & 0.029 & 0.030 & 0.044 \\
\hline ARE & 0.013 & 0.021 & 0.025 & 0.025 & 0.038 \\
\hline ARS & 0.017 & 0.038 & 0.029 & 0.029 & 0.045 \\
\hline
\end{tabular}

The design of adsorption systems is strongly related to the adsorption kinetic data which are the basic requirements. In order to optimize the design of a specific sorbate/sorbent system to remove MB from aqueous solution, it is important to establish the most appropriate correlation for the experimental kinetic data. Applicability of some statistical tools to predict optimum adsorption kinetic of MB onto AC after linear regression analysis showed that the highest $\mathrm{R}^{2}$ value and the lowest ARE, ARS, MSPED, and HYBRID values could be suitable and meaningful tools to predict the best-fitting equation models. The best fitting is determined based on the use of these functions to calculate the error deviation between experimental and predicted equilibrium adsorption kinetic data, after linear analysis. The adsorption phenomenon was satisfactorily described by the linear Elovich model (type 1 and 2) (Table 6). Therefore, based on these mentioned results, the best useful error based on such statistical tools should point out the linear Elovich model (type 1 and 2) followed by linear Pseudo-second order (type 9 and 10), non linear Esquivel, non linear Pseudo-second order and linear Esquivel as the best-fitting models.

Activated carbon, produced from the residue of Sapindus fruit, was used for the adsorption of Methylene bleu in simulated aqueous solution. In batch mode, the adsorption was highly dependent on two operating parameters ( $\mathrm{pH}$, contact time). The obtained results revealed the following optimal conditions: $\mathrm{pH}$ value of 6 and $120 \mathrm{~min}$ of contact time, which lead to $98 \%$ MB removal.

Kinetics data correlated well with the linear Elovich model (type 1 and 2), whereas equilibrium study was best described by non-linear Freundlich isotherm model.

The adsorption kinetic of MB onto AC can be better fitted by the linear Elovich model (type 1 and 2), as 
compared to the linear Pseudo first order, non linear Pseudo first order, the non-linear Pseudo-second-order model, linear Pseudo-second-order model, Pseudo third order, linear Esquivel and non linear Esquivel models. AC is suitable adsorbent for the removal of $\mathrm{MB}$ as showed by the entire experimental results.

\section{REFERENCES}

Al-Degs, Y.S., Sweileh, J.A. 2012. Simultaneous determination of five commercial cationic dyes in stream waters using diatomite solid-phase extractant and multivariate calibration. Arabian Journal of Chemistry, 5: 219-224.

Allen, S.J., Koumanova, B. 2005. Decolourisation of water/wastewater using adsorption. Journal of the University of Chemical Technology and Metallurgy, 40(3): 175-192.

Amin, M.T., Alazba, A.A., Shafiq, M. 2017. Effective adsorption of methylene blue dye using activated carbon developed from the rosemary plant: isotherms and kinetic studies. Desalination and Water Treatment, 74: $336-345$.

Benkhedda, J., Jaubert, J.N., Barth, D. 2000. Experimental and modeled results describing the adsorption of toluene onto activated carbon. Journal of Chemical and Engineering Data, 45:650-653.

Blanachard,G., Maunaye,M., Martin,G. 1984. Removal of heavy metals from waters by means of natural zeolites. Water Research, 18(12): 1501-1507.

Dahri, M.K., Kooh, M.R.R., Lim, L.B.L. 2014. Water remediation using low cost adsorbent walnut shell for removal of malachite green: Equilibrium; kinetics; thermodynamic and regeneration studies. Journal of Environmental Chemical Engineering, 2(3): 1434-1444.

De Ridder, D.J. 2012. Adsorption of organic micropollutants onto activated carbon and zeolites. Published by Water Management Academic Press, Netherlands

Fadi Al Mardini, Bernard Legube. 2009. Effect of the adsorbate (Bromacil) equilibrium concentration in water on its adsorption on powdered activated carbon. Part 1. Equilibrium parameters. Journal of Hazardous Materials, 170: 744-753.

Gulipall, C.S., Prasad, B., Wasewar KL. 2011. Batch study; equilibrium; and kinetics of adsorption of selenium using Rice Husk Ash (RHA). Journal of Engineering Science and Technology, 6(5): 586-605.

Han, R., Zhang, V., Han, P., Wang, Y., Zhao, Z., Tang, M. 2009. Study of equilibrium; kinetic and thermodynamic parameters about methylene blue adsorption onto natural zeolite. Chemical Engineering Journal, 145: 496-504.

He, J., Hong, S., Zhang, L., Gan, F., Ho, Y.S. 2010. Equilibrium and thermodynamic parameters of adsorption of methylene blue onto rectorite. Fresenius Environmental Bulletin, 19(11): 2651-2656.

Ho, Y.S. 2006. Second-order kinetic model for the sorption of cadmium onto tree fern: A comparison of linear and nonlinear methods. Water Research, 40: 119 - 125.

Ho, Y.S., Ng, J.C.Y., McKay, G. 2000. Kinetics of pollutant sorption by biosorbents. Review: Separation and Purification Methods, 29(2): 189-232.

Ho, Y.S., McKay, G. 2002. Application of Kinetic Models to the Sorption of Copper(II) on to Peat. Adsorption Science \& Technology, 20(8): 797-815.

Khattria, S.D., Singh, M.K. 2009. Removal of malachite green from dye wastewater using neem sawdust by adsorption. Journal of Hazardous Materials, 167: 1089-1094.

Kumar, K.V. 2006. Linear and non-linear regression analysis for the sorption kinetics of methylene blue onto activated carbon. Journal of Hazardous Materials, B137: 1538-1544.

Kushwaha, A.K., Gupta, N., Chattopadhyaya, M.C., 2014. Removal of cationic methylene blue and malachite green dyes from aqueous solution by waste materials of Daucus carota. Journal of Saudi Chemical Society, 18:200-207.

Lam, M.K., Dzuan, Z. 2008. Production of activated carbon from sawdust using fluidized bed reactor. International Conference on Environment (ICENV)

Marouf-Khelifa, K., Khelifa, A., Belhakem, A., Marouf, R., Abdelmalek, F., Addou, A. 2004. The adsorption of pentachlorophenol from aqueuous solution onto exchanged Al-MCM-41 materials. Adsorption Science and Technology, 22(1): 1-12.

Marrakchi, F., Bouaziz, M., Hameed, B.H. 2017. Adsorption of acid blue 29 and methylene blue on mesoporous $\mathrm{K}_{2} \mathrm{CO}_{3}$-activated olive pomace boiler ash. Colloids and Surfaces A, 535: 157-165.

Ncibi, M.C. 2008. Applicability of some statistical tools to predict optimum adsorption isotherm after linear and non-linear regression analysis. Journal of Hazardous Materials, 153: 207-212.

Ouldmoumna, A., Laurence Reinert, Nouredine Benderdoucheb, Benaouda Bestani, Laurent Duclaux. 2013. Characterization and application of three novel biosorbents "Eucalyptus globulus, Cynara cardunculus, and Prunus cerasefera" to dye removal. Desalination and Water Treatment, 51: 3527-3538

Pathania, D., Sharma, S., Singh, P. 2017. Removal of methylene blue by adsorption onto activated carbon developed from Ficus carica bast. Arabian Journal of Chemistry, 10: 1445-1451.

Pereira, L., Alves, M., Malik, A., Grohmann, E. 2012. Dyes-Environmental Impact and Remediation. eds. Environmental Protection Strategies for Sustainable Development, Strategies for Sustainability, 111-162. DOl I 0.1007/978-94- 
007-1 591-2_4, Springer Science+Business Media B.V.

Rao, V.S., Chakrapani, C., Babu, CS., Rao, KS., Rao, MN., Sinha, D. 2011. Studies on sorption of fluoride by prepared activated Kaza's carbons. Der Pharma Chemica, 3(3): 73-83.

Sakr, F., Sennaoui, A., Elouardi, M., Tamimi, M., Assabbane, A. 2015. Adsorption study of Methylene Blue on biomaterial using cactus. J. Mater. Environ. Sci., 6(2): 397-406.

Santhi, T., Manonmani, S., Smitha, T., Mahalakshmi, K. 2009. Adsorption kinetics of cationic dyes from aqueous solution by bioadsorption onto activated carbon prepared from Cucumis Sativa. Journal of Applied Sciences in Environmental Sanitation, 4(3): 263-271.

Shilpi, A., Shivhare, US., Basu, S. 2013. Supercritical $\mathrm{CO}_{2}$ Extraction of Compounds with Antioxidant Activity from Fruits and Vegetables Waste. Focusing on Modern Food Industry 2(1): 43-62.

Tavlieva, M.P., Genieva, S.D., Georgieva, V.G., Vlaev, L.T. 2013. Kinetic study of brilliant green adsorption from aqueous solution onto white rice husk ash. Journal of Colloid and Interface Science, 409: 112-122. 